1. MBBS, MPH, MRCP (UK) Lecturer, Community Department, Ayub Medical College, Abbottabad. 2. MBBS

Lecturer, Pathology Department, Ayub Medical College Abbottabad

3. Student of $3^{\text {rd }}$ year MBBS

Ayub Medical College Abbottabad.

4. MBBS

Resident Medicine Department

5. MBBS, MRCP

Lecturer, Pathology Department,

Ayub Medical College.

6. MBBS, MPH

Certified UPH, Newyork, USA

Resident Orthopaedics Surgeon, Ghurki Trust Teaching Hospital,

Lahore.

Correspondence Address:

Dr. Ashfaq Ahmed

MBBS, MPH

Certified UPH, Newyork, USA

Resident Orthopaedics Surgeon,

Ghurki Trust Teaching Hospital,

Lahore.

ashfaqjadoon40@yahoo.com

Article received on:

13/02/2016

Accepted for publication:

20/05/2017

Received after proof reading:

08/08/2017

\section{PRE-DIABETES; PREVALENCE IN STUDENTS OF AYUB MEDICAL COLLEGE, ABBOTTABAD.}

Rabnawaz Khan ${ }^{1}$, Sundus Khan ${ }^{2}$, Sumbul Gul ${ }^{3}$, Shamsa kanwal ${ }^{4}$, Ariz Samin ${ }^{5}$, Ashfaq Ahmed ${ }^{6}$

ABSTRACT... Objectives: To determine the prevalence of pre diabetes in students of Ayub Medical College and associated risk factors. Study Design: Prospective study. Period: Jan 2016 to Jun 2016. Setting: Ayub Medical College. Materials and Methodology: 130 students participated after simple random sampling technique. Different variables were studied and initially were entered on a pre-formed proforma and then SPSS 17.0 version were used for data analysis. Results: $15(11.54 \%)$ of the students were suffering from pre diabetes. Among them $11(8.46 \%)$ were males while $4(3.07 \%)$ were females. 50 (38.46\%) students had a positive family history of diabetes whereas $80(61.54 \%)$ had no family history. $111(85.38 \%)$ of the students in study were non-smokers and Only $40(30.77 \%)$ students were doing regular exercise. Conclusion: A significant prevalence of pre-diabetes in young adults is a matter of concern therefore all young adults need to be targeted for screening of pre diabetes and lifestyle modification.

Key words: $\quad$ Prevalence, Pre diabetes, Students, Risk factors.

Article Citation: Khan R, Khan S, Gul S, Kanwal S, Samin A, Ahmed A. Pre-diabetes; Prevalence in students of Ayub Medical College, Abbottabad.. Professional Med J 2017;24(8):1190-1194. DOI: 10.17957/TPMJ/17.3880

\section{INTRODUCTION}

Pre-diabetes is a term is mostly used in medical world for the person is at risk of developing diabetes. So that we can cure it by starting its treatment. The person suffering from it having blood sugar level above normal but below the range of diabetes, so mostly it is called as Border line Diabetes. ${ }^{1}$ The regulation of body glucose level is under the control of an hormone called Insulin. In Pre-diabetes our body might not be able to construct enough insulin after eating, or our body may not react to insulin. ${ }^{2}$ Prediabetes contains impaired fasting glucose or impaired glucose tolerance and increases the risk factor for developing type 2 diabetes, micro vascular, and macro vascular diseases. ${ }^{3}$ The old terminology of Border line had been replance by new term Impaired Glucose Tolerance in 1979 by World Health Organization and National Diabetes Data Group, in 1965, chemical or asymptomatic DM was coined. ${ }^{4}$ In 1997, an expert committee from the American Diabetes Association (ADA) recommended the following criteria for PDM; a fasting blood glucose of 110 to $<126 \mathrm{mg} / \mathrm{dl}$ and/or a postprandial blood glucose of 140 to $<200 \mathrm{mg} /$ dl 2 hours after a $75 \mathrm{~g}$ oral glucose challenge. The new word i-e Pre-diabetes mellitus was first introduced in 2002 by the Department of Health and Human services and ADA, to replace IGT and a change in the term was introduced to highlight the seriousness of the condition and to motivate health givers andto motivate it more attention. ${ }^{5}$

The prevalence of diabetes around world is about 346 million, which is a serious issue and disease because of its many complications associated with it. A data in 2004 found that about 3.4 million people are died because of this devastating disease and more than $80 \%$ of deaths occur in developing countries. The most important cause of this disease is because of physical in activity and obesity. ${ }^{6}$ Adolescents and young adults who are suffering from DM are believed to loss 15 years from their expected life and may practice severe difficulties by their forties. ${ }^{7}$ A large multicenter study of physician-diagnosed diabetes between youth 0-19 years of age, gives rate of prevalence and incidence of Type 2 DM. In 2012 the 
prevalence of Type 2 diabetes Mellitus scarce among non-Hispanic white youths. It was 0.18 in 1000 between the individuals of $10-19$ years, with an occurrence of 3.7 per 100,000 persons during 4 year study. ${ }^{8}$ Among African and Americans the rates of prevalence and incidence was high i.e. 1.06 in 1000, 19.0 per 100,000, In Hispanic (0.46, 11.6), and Asian/Pacific it is about $0.52,12.1$ than non-Hispanic white youth. ${ }^{9}$ Different programs were arranged to decrease the frequency and prevalence of diabetes. According to one program i-e Diabetes Prevention Program if we decrease the body weight and do more physical activity the prevalence of pre diabetes can be decreased by $58 \%{ }^{10}$ Another program i-e Lawrence Latino Diabetes Prevention Project was designed to reduce the different factors which predispose to the pre diabetes like obesity, fasty glucose level, blood pressure, body mass index and many other factors. ${ }^{11}$ Ramachandran concluded in their study that there are several options to decrease the occurrence of pre diabetes like the prevalence like use of grains and non-starchy foods, reduce intake of saturated fats and hydrogenated fats, sodium sat, use of smaller meals rather than taking larger meals, increase use of vegetables, fibers and water intake and physical activity about 1 hour per day. ${ }^{12}$

There is a gap of knowledge regarding the pre diabetes in our population. The aim of this study was to determine the prevalence of pre diabetes in medical students and the various risk factors associated with them.

\section{MATERIALS AND METHODOLOGY}

It was a prospective study on 130 students, selected through probability random sampling technique from five different classes from Jan 2016 to June 2016 at Ayub Medical College, Abbottabad, Pakistan. 26 students were selected from each class of MBBS. The students of any age and gender who were willing to be a part of the study were included in the study. The students who refused to be a part of it or those with known diabetes or pre diabetes were excluded from the study. The study was conducted after taking approval from College Ethical Committee and informed consent from the students. Different variables were studies like age, sex, BMI, Random Blood Sugar, family history, Cigareette smoking, Physical activity, etc.Cigarette smoking was defined as having smoked at least 100 cigarettes in one's lifetime. Regular leisure-time physical activity was defined as participation in moderate or vigorous activity for 30 minutes or more per day at least 3 days a week We used American Diabetes Association criteria for considering an individual normal, prediabetic or diabetic. Blood sugar level below 100 was considered normal; between 100 and $125 \mathrm{mg} / \mathrm{dl}$ was considered prediabetic; and above $126 \mathrm{mg} / \mathrm{dl}$ was considered as indicative of diabetes mellitus. Body weight was estimated, using Krup's weighing machine, with a least count of $0.5 \mathrm{~kg}$. The subject was made to stand on the weighing scale, feet around $15 \mathrm{~cm}$ apart, and weight distributed on both the legs. Zero setting was done before each measurement. Height was estimated, with the subject standing upright against the wall such that the roof of the external auditory meatus was in line with the lower margin of the orbit. A hard board was placed on the wall, just over the head and height was marked on the wall and measured with a measuring tape with a least count of 0.5 $\mathrm{cm}$. The fasting blood sugar were measured at morning after advising protocol to students 1 day before sampling. The blood sample were taken using aseptic measures at hospital laboratory by same expert technician in all students. The data were initially entered on a pre-formed proforma and then were entered at SPSS 17.0 version. Descriptive statistics were measured as mean \pm S.D. The figures and graphs were used where necessary. Pearson's Chi square test was applied to study the difference between categorical variables. Student's $t$-test was used to analyse the difference between continuous variables.

\section{RESULTS}

130 students responded and participated in our study with mean age of $21.53 \pm 1.732$ years ranges from 18 to 25 years. Majority of them were males i-e $80(61.54 \%)$ and 50 (38.46\%) were females. $115(88.46 \%)$ of the students having normal blood glucose level while the remaining 
showed pre diabetes i-e 15(11.54\%). Among them $11(8.46 \%)$ were males while $4(3.07 \%)$ were females. All the students with normal blood sugar having Random Blood Glucose level less than $100 \mathrm{mg} / \mathrm{dl}$ while the remaining showed blood glucose level between 100mg/dl to $126 \mathrm{mg} / \mathrm{dl}$. Of the data collected the minimum blood glucose level was 70 whereas the maximum was 108 with mean of $90.53 \pm 7.41$. None of the student glucose level were above to it.

The mean Body Mass Index were 22.6491 \pm 3.037 . According to the data collected, 50 (38.46\%) students had a positive family history of diabetes whereas $80(61.54 \%)$ had no family history. Students were also asked about their family income. The question was kept optional. 26 students did not respond to it. Of the remaining 103 students 23 had family income in the range of 30000-50000, 40 between 50000-80000, and 40 had more than 80000 . Keeping in view the relationship between smoking and prediabetes, smoking status was also inquired. 19(14.7\%) were either smokers or had smoked in the past. $111(85.38 \%)$ of the students in study was nonsmokers. Only 40(30.77\%) students were doing regular exercise while remaining were not. The pre diabetes were cross tabulated with age, obesity, lack of exercise and family history but statistically insignificant. $p>0.05$. The summary of the risk factors and prevalence of pre diabetes in different students along with $p$ value are summarized in Table-I.

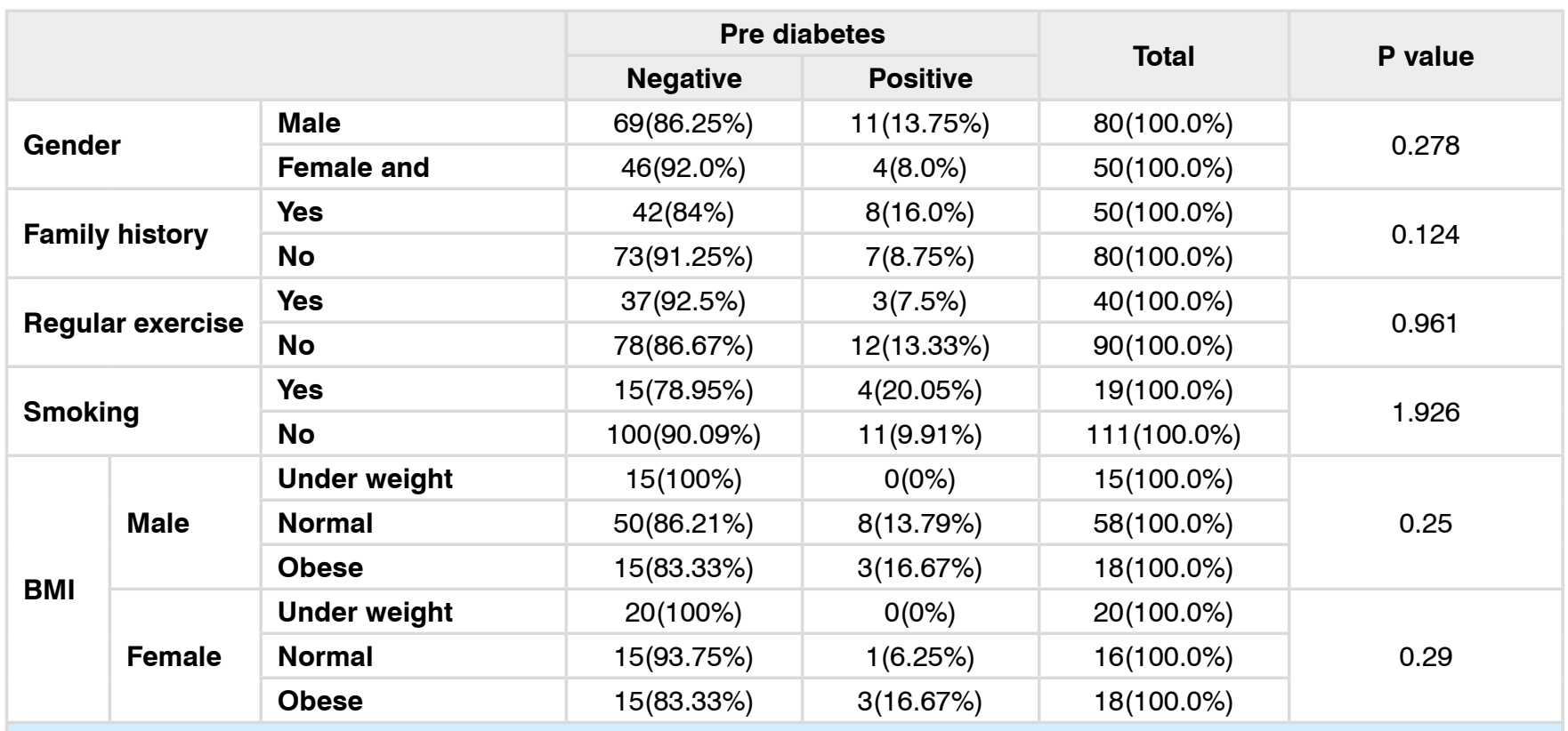

Table-I. Distribution of risk factors and prevalence of prediabetes

\section{DISCUSSION}

The blood glucose level are now rapidly deranging in developed countries. 2.7 million Adults that took part in health surveys estimate the level of Fasting Plasma Glucose was $5.5 \mathrm{mmol} / \mathrm{L}$ in men and $5.4 \mathrm{mmol} / \mathrm{L}$ in women in 2008 , a rise of $0.1 \mathrm{mmol} / \mathrm{L}$ since 1980 . Like other developed countries the pre diabetic conditions had been increasing in United States of America. ${ }^{13}$ Pre diabetes is a silent killer which kills the patient without informing him a lot. It is mostly due to lack of knowledge about signs and symptoms of diabetes. So, every patient having family history of diabetes or other risk factor should have a regular checkup about this condition. These patients mostly having weight loss, hunger, flu like symptoms like fever, headache due to decrease immunity, blurred vision, slow healing of cuts and bruises, tingling or loss of feeling in hands and feet. ${ }^{14,15}$ There are numerous causes of this condition like family history, sleep disturbance, high level of triglycerides, low level of good cholesterol. ${ }^{15}$ Prediabetes prevalence varied by age, sex, and race/ethnicity, and there was 
considerable discordance between measures of pre diabetes. ${ }^{16}$

In our study only 15 students were pre diabetics and mostly males were affected i.e $14.1 \%$ as compared to females which were $7.8 \%$. Similar findings were found in other studies having male predominancy. ${ }^{17-19}$ While the study conducted at Hyderabad it was found that pre diabetes were more prevalent in females. ${ }^{20}$ The difference between the percentages of male and female may be because our study was on the students of Ayub Medical College and most of the students were aware of sign and symptoms of diabetes, so they were conscious about their health for which they had special control on their diet as well as the male students were more in frequency as compared to females. In our study only 3 patients having high BMl who were suffering from pre diabetes while remaining students having $\mathrm{BMI}$ within normal range. Li $\mathrm{C}$ et all found that overweight adolescents had a 2.6-fold higher rate than those with normal weight ${ }^{18}$ Similarly the study conducted at China and Kuwait, the prevalence of prediabetes were $3.8 \%$ and $6.8 \%$ respectively more in obese. ${ }^{20,23}$ On other hand, other studies concluded that obesity is not a significant risk factor. ${ }^{19,21,22}$ While in our study the prevalence of prediabetes in obese is $40 \%$ which is much high than other studies. There are so many other risk factors. Smoking is one of the risk factor that can also cause prediabetes. In our study the total number of smokers were $19(14.62 \%)$. Among them only $4(21.05 \%)$ were found to be suffering from pre diabetes. Abdulbari Bener study concluded that smoking and family history are important contributors to Diabetes. ${ }^{20}$ The study in India found that smoking, obesity, family history and sedentary life style are important risk factors for pre diabetes. ${ }^{23}$ Similarly Amaranth et all found that the students are high risk of pre diabetes who having obesity, family history ,fast food consumption and physical inactivity. ${ }^{24}$

There are some limitations in our study. The dietary habits of the patients were not studied and the students were only medical students. Most of them were aware about the precautions. So, further studies needed in general population to give more valuable results about the prevalence of pre diabetes.

\section{CONCLUSION}

The prevalence of pre diabetes is much high among medical students. Not only medical students but other students with risk factors should be examined for pre diabetes and thus to prevent them from future type 2 diabetes mellitus. Community health programs needed for awareness among non-medical adults.

Copyright@ 20 May, 2017.

\section{REFERENCES}

1. Ramachandran A, Snehalatha C, Satyavani K, Sivasankari S, Vijay V. Type 2 diabetes in Asian-Indian urban children. Diabetes care. 2003;26(4):1022-5.

2. Shrot RJ, Sahebzamani FM, Brownlee HJ. Case study: screening and treatment of pre-diabetes in primary care. Clinical Diabetes. 2004;22(2):98-100.

3. Narayanappa D, Rajani H, Mahendrappa K, Prabhakar A. Prevalence of prediabetes in school-going children. Indian pediatrics. 2011;48(4):295-9.

4. Miller JH, Bogdonoff MD. Antidiuresis associated with administration of insulin. Journal of applied physiology. 1954;6(8):509-12.

5. Katikireddi SV, Morling JR, Bhopal R. Is there a divergence in time trends in the prevalence of impaired glucose tolerance and diabetes? A systematic review in South Asian populations. International journal of epidemiology. 2011;40(6):154253.

6. Pan A, Schernhammer ES, Sun Q, Hu FB. Rotating night shift work and risk of type 2 diabetes: two prospective cohort studies in women. PLoS Med. 2011;8(12):e1001141.

7. Bell RA, Mayer-Davis EJ, Beyer JW, D'Agostino RB, Lawrence JM, Linder $B$, et al. Diabetes in NonHispanic White Youth Prevalence, incidence, and clinical characteristics: the SEARCH for Diabetes in Youth Study. Diabetes care. 2009;32(Supplement 2):S102-S11.

8. Mayer-Davis EJ, Beyer J, Bell RA, Dabelea D, D'Agostino $R$, Imperatore $G$, et al. Diabetes in African American Youth Prevalence, incidence, and clinical characteristics: the SEARCH for Diabetes in Youth Study. Diabetes care. 2009;32(Supplement 2):S112-S22. 
9. Rahim M, Rahim M, Qureshi MA, Sharafat S, Shaikh Z, Rahim MA, et al. Serum Insulin and Insulin Resistance in the Off-Springs of Type 2 Diabetes Mellitus. Journal of Diabetes \& Metabolism. 2014;2014.

10. Merriam PA, Tellez TL, Rosal MC, Olendzki BC, Ma Y, Pagoto SL, et al. Methodology of a diabetes prevention translational research project utilizing a community-academic partnership for implementation in an underserved Latino community. BMC medical research methodology. 2009;9(1):1.

11. Jabbar A, Hameed A, Chawla R, Akhter J. How well do Pakistani patients and physicians adhere to standards of diabetes care. Int J Diab Dev Ctries. 2007;27(3):93-6.

12. Ramachandran A, Snehalatha $C$, Shetty AS, Nanditha A. Trends in prevalence of diabetes in Asian countries. World J Diabetes. 2012;3(6):110-7.

13. Danaei G, Finucane MM, Lu Y, Singh GM, Cowan MJ, Paciorek CJ, et al. National, regional, and global trends in fasting plasma glucose and diabetes prevalence since 1980: systematic analysis of health examination surveys and epidemiological studies with $\mathbf{3 7 0}$ country-years and $\mathbf{2 \cdot \mathbf { 7 }}$ million participants. The Lancet. 2011;378(9785):31-40.

14. Greenhalgh T, Howick J, Maskrey N. Evidence based medicine: a movement in crisis? 2014.

15. Mainous AG, Tanner RJ, Baker R, Zayas CE, Harle CA. Prevalence of prediabetes in England from 2003 to 2011: population-based, cross-sectional study. BMJ open. 2014;4(6):e005002.

16. James C, Bullard KM, Rolka DB, Geiss LS, Williams DE, Cowie CC, et al. Implications of alternative definitions of prediabetes for prevalence in US adults. Diabetes care. $2011 ; 34(2): 387-91$.
17. Jeon JY, Ko S-H, Kwon H-S, Kim NH, Kim JH, Kim $\mathrm{CS}$, et al. Prevalence of diabetes and prediabetes according to fasting plasma glucose and HbA1c. Diabetes \& metabolism journal. 2013;37(5):349-57.

18. Li C, Ford ES, Zhao G, Mokdad AH. Prevalence of pre-diabetes and its association with clustering of cardiometabolic risk factors and hyperinsulinemia among US adolescents National Health and Nutrition Examination Survey 2005-2006. Diabetes care. 2009;32(2):342-7.

19. Yang W, Lu J, Weng J, Jia W, Ji L, Xiao J, et al. Prevalence of diabetes among men and women in China. New England Journal of Medicine. 2010;362(12):1090-101.

20. Bener A, Zirie M, Janahi IM, Al-Hamaq AO, Musallam $M$, Wareham NJ. Prevalence of diagnosed and undiagnosed diabetes mellitus and its risk factors in a population-based study of Qatar. Diabetes Research and Clinical Practice. 2009;84(1):99-106.

21. Sinha R, Fisch G, Teague B, Tamborlane WV, Banyas $B$, Allen $K$, et al. Prevalence of impaired glucose tolerance among children and adolescents with marked obesity. New England Journal of Medicine. 2002;346(11):802-10.

22. Zhu H, Zhang X, Li MZ, Xie J, Yang XL. Prevalence of Type 2 diabetes and pre $\square$ diabetes among overweight or obese children in Tianjin, China. Diabetic Medicine. 2013;30(12):1457-65.

23. Bhattacharya PK, Iqbal A. Evaluation of risk of type 2 diabetes mellitus and prediabetes in students of health institutions in a northeast Indian city. Indian Journal of Medical Specialities. 2016;7(1):3-8.

24. Amarnath M, Prasad V, Reddy N. Pre-diabetes among Medical students in a Medical College, Andhra Pradesh. Indian Journal of Public Health Research \& Development. 2014;5(4):209-14.

\begin{tabular}{|c|c|c|c|}
\hline \multicolumn{4}{|c|}{ AUTHORSHIP AND CONTRIBUTION DECLARATION } \\
\hline Sr. \# & Author-s Full Name & Contribution to the paper & Author $=\mathbf{s}$ Signature \\
\hline 1 & Dr. Rabnawaz Khan & Study design & \pm \\
\hline 2 & (2) & (a) & \\
\hline 3 & Dr. Sumbul Gul & Data collection & 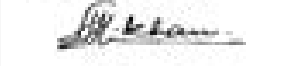 \\
\hline 4 & Dr. Shamsa kanwal & Data analysis & Hthent $\rightarrow$ \\
\hline 5 & Dr. Ariz Samin & Data analysis & \\
\hline 6 & Dr. Ashfaq Ahmed & $\begin{array}{l}\text { Article writing and critical } \\
\text { review }\end{array}$ & \\
\hline
\end{tabular}

